\title{
A process-based emission model of volatile organic compounds from silage sources on
}

\section{farms}

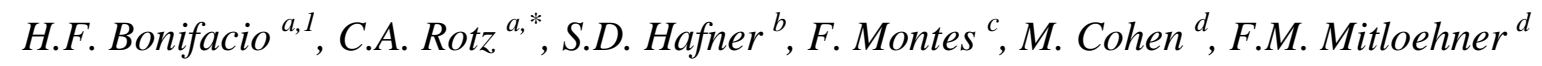

${ }^{a}$ Pasture Systems and Watershed Management Research Unit, USDA Agricultural Research Service, University Park, PA, USA

${ }^{b}$ Department of Chemical Engineering, Biotechnology and Environmental Technology, University of Southern Denmark, Odense, Denmark

${ }^{c}$ Plant Science Department, The Pennsylvania State University, University Park, PA USA

${ }^{d}$ Department of Animal Science, University of California, Davis, CA, USA

* Corresponding author. E-mail address: Al.Rotz@ars.usda.gov.

${ }^{1}$ Present address: Air Quality Program, Northwest Regional Office, Pennsylvania Department of Environmental Protection, Meadville, PA, USA

\begin{abstract}
Silage on dairy farms can emit large amounts of volatile organic compounds (VOCs), a precursor in the formation of tropospheric ozone. Because of the challenges associated with direct measurements, process-based modeling is another approach for estimating emissions of air pollutants from sources such as those from dairy farms. A process-based model for predicting VOC emissions from silage was developed and incorporated into the Integrated Farm System Model (IFSM, v. 4.3), a whole-farm simulation of crop, dairy, and beef production systems. The performance of the IFSM silage VOC emission model was evaluated using ethanol and methanol emissions measured from conventional silage piles (CSP), silage bags (SB), total mixed rations
\end{abstract}


(TMR), and loose corn silage (LCS) at a commercial dairy farm in central California. With transport coefficients for ethanol refined using experimental data from our previous studies, the model performed well in simulating ethanol emission from CSP, TMR, and LCS; its lower performance for SB could be attributed to possible changes in face conditions of SB after silage removal that are not represented in the current model. For methanol emission, lack of experimental data for refinement likely caused the underprediction for CSP and SB whereas the overprediction observed for TMR can be explained as uncertainty in measurements. Despite these limitations, the model is a valuable tool for comparing silage management options and evaluating their relative effects on the overall performance, economics, and environmental impacts of farm production. As a component of IFSM, the silage VOC emission model was used to simulate a representative dairy farm in central California. The simulation showed most silage VOC emissions were from feed lying in feed lanes and not from the exposed face of silage storages. This suggests that mitigation efforts, particularly in areas prone to ozone nonattainment status, should focus on reducing emissions during feeding. For the simulated dairy farm, a reduction of around $30 \%$ was found if cows were housed and fed in a barn rather than in an open lot, and 23\% if feeds were delivered as four feedings per day rather than as one. Reducing the exposed face of storage can also be useful. Simulated use of silage bags resulted in $90 \%$ and $18 \%$ reductions in emissions from the storage face and whole farm, respectively.

\section{KEYWORDS}

Volatile organic compounds, Silage, Dairy farm, Emissions, Process-based model, Integrated Farm System Model 


\section{Introduction}

Confined animal facilities, such as dairy farms, have been identified as major contributors of volatile organic compounds (VOCs) in the San Joaquin Valley of California, USA (SJVAPD, 2016). In the presence of sunlight, VOCs emitted to the air can react with oxides of nitrogen $\left(\mathrm{NO}_{\mathrm{x}}\right)$ to form ground-level ozone, one of six criteria air pollutants regulated by USEPA (2016). Based on recent studies, total mixed rations (TMR) in feed lanes contribute most to VOC emissions from dairy farms, followed by silage storages (Alanis et al., 2008; Chung et al., 2010). Quantifying the contribution of animal facilities to ground-level ozone formation requires accurate estimates of VOCs emitted from different silage sources. Published VOC emissions from silage have been measured using isolation flux chambers (Alanis et al., 2008; Chung et al., 2009), large environmental chambers (Howard et al., 2010), and wind tunnel systems (Hafner et al., 2010b; Montes et al., 2010). The few on-farm measurements available have been determined using flux chambers operated at low air flow rates (e.g., Alanis et al., 2008; Chung et al., 2009) and may only represent VOC emissions under very light or no wind conditions. Use of direct measurements to quantify VOC emissions on-farm and evaluate trends of VOC emissions under different silage management strategies also can be costly, time-consuming, and labor-intensive.

Process-based modeling is a promising technique for predicting VOC emissions from various sources on farms. With this approach, important processes contributing to emissions of VOCs are simulated using mathematical relationships. Our group has conducted studies to identify and better understand parameters and processes influencing VOC emissions from silage (Hafner et al., 2009; Hafner et al., 2010b; Montes et al., 2010). We also have been involved in the development of two models for predicting VOC emissions from silage - the convection model by El-Mashad et al. (2010) and the convection-diffusion model by Hafner et al. (2012). 
Although performances of these models have already been evaluated, they are not ideal for incorporation into our whole-farm simulation model (Integrated Farm System Model, IFSM;

Rotz et al., 2016). Designed for loose, thin layers of silage, the model by El-Mashad et al. (2010) cannot be used to simulate all types of silage within a farm, such as the compacted silage in storages and the loose silage in feed lanes with depths greater than $3 \mathrm{~cm}$. The convectiondiffusion model derived by Hafner et al. (2012) can account for effects of various silage source properties (e.g., density, porosity, moisture content, and depth) on VOC emissions. However, the analytical solution used in Hafner et al. (2012) is computationally intensive and thus cumbersome in whole-farm simulation.

The objective of this work was to develop a process-based model that can accurately and efficiently predict VOC emissions from different silage sources on farms for incorporation in IFSM. The IFSM silage VOC emission model presented is essentially a solution of the convection-diffusion model by Hafner et al. (2012) that is much less computationally intensive compared to the analytical solution. As a component of IFSM, the silage VOC emission model can be used to assess both individual sources' and the whole farm's potential to emit VOCs as affected by silage management practices and climate. In this paper, we: (1) provide relationships used in simulating VOC emissions from silage storages, feed mixing and feed lanes; (2) evaluate model performance for silage storages and feed lanes using measurements at a commercial dairy farm; and (3) demonstrate the model in whole-farm evaluation of various silage management strategies. Following other studies (Zhang et al., 2010; Malkina et al., 2011), emission data used in evaluating the model were ethanol and methanol measurements from various silage sources at a California dairy farm (Mitloehner et al., 2016). Alcohols, primarily ethanol, contribute most to VOC emissions from and ozone formation potential due to silage (Howard et al., 2010; Malkina 
et al., 2011; Hafner et al., 2013). Still, other VOCs such as acids, which have the highest mass in silage, and esters and aldehydes, both of which have higher volatility, can further the overall ozone formation potential of silage emissions (Hafner et al., 2013).

\section{Model Description}

The silage VOC emission model has two components: one for predicting VOC emissions from silage storages and feed lanes, and the other for simulating VOC losses during feed mixing. The component for silage storages and feed lanes is a numerical solution to the convectiondiffusion model by Hafner et al. (2012) with negligible computation time. Relationships for estimating VOC transport parameters and defining computational domains were derived using measurement data from our previous wind tunnel studies. The performance of this component was evaluated using field measurements (Section 3).

A simpler approach is used in simulating VOC losses during feed mixing. We assume that all VOC present in the gaseous phase within silage are released into the atmosphere while silage and other TMR ingredients are being mixed. This component, which predicts a relatively small emission, was not evaluated due to the absence of applicable measured data.

\subsection{Silage Storage and Feed Lanes}

The component used to simulate silage storages and feed lanes was developed based upon the one-dimensional convection-diffusion model by Hafner et al. (2012). The emission of VOCs from the exposed silage surface is simulated through convection while its transport within silage is simulated as diffusion in both gaseous and aqueous phases (Hafner et al., 2012).

Limitations inherent to the convection-diffusion model (i.e., no VOC production nor destruction after fermentation, negligible VOC sorption to particles, gaseous-aqueous phase equilibrium, etc.; Hafner et al., 2012), also apply to the simulation model we developed. 


\subsubsection{Emission and Transport Equations}

Based on the convection-diffusion model (Hafner et al., 2012), VOC emission flux from the silage surface $\left(j_{\text {sur }}\right)\left(\mathrm{g} \mathrm{m}^{-2} \mathrm{~s}^{-1}\right)$ is given by:

$$
j_{\text {sur }}=\alpha C_{b, \text { sur }}
$$

where $\alpha=$ effective surface mass transfer coefficient of the $\operatorname{VOC}\left(\mathrm{m} \mathrm{s}^{-1}\right)$, and $C_{b, s u r}=$ bulk VOC concentration (i.e., total in both gaseous and aqueous phases) at the silage surface $\left(\mathrm{g} \mathrm{m}^{-3}\right)$. The VOC concentration in ambient air is assumed negligible. Transport flux of the VOC within silage $(j)\left(\mathrm{g} \mathrm{m}^{-2} \mathrm{~s}^{-1}\right)$ is given by:

$$
j=-D_{b} \frac{d C_{b}}{d x}
$$

where $D_{b}=$ effective diffusion mass transfer coefficient $\left(\mathrm{m}^{2} \mathrm{~s}^{-1}\right), C_{b}=$ bulk VOC concentration within silage $\left(\mathrm{g} \mathrm{m}^{-3}\right)$, and $x=$ depth from the midpoint to the top edge of the silage layer modeled (m). Parameters $\alpha$ and $D_{b}$ are calculated as functions of silage characteristics and VOC properties (Hafner et al., 2012). The $\alpha$ is calculated as:

$$
\alpha=\frac{h_{m}}{H \rho_{w} w+\varnothing}
$$

where $h_{m}=$ gas-phase mass transfer coefficient of the VOC $\left(\mathrm{m} \mathrm{s}^{-1}\right), H=$ concentration-based Henry's law constant $\left(\mathrm{m}^{3} \mathrm{~kg}^{-1}\right), \rho_{w}=$ silage wet density $\left(\mathrm{kg} \mathrm{m}^{-3}\right), w=$ gravimetric water content $\left(\mathrm{kg} \mathrm{kg}^{-1}\right)$, and $\phi=$ gas-phase porosity $\left(\mathrm{m}^{3} \mathrm{~m}^{-3}\right)$. Because effective mass transfer in the gaseous phase (e.g., see Eq. (7) below) can be several orders of magnitude higher than that in the aqueous phase (e.g., Penman-Millington-Quirk model (Hafner et al., 2012)), $D_{b}$ is based on gas diffusion only:

$$
D_{b}=\frac{k_{s g}}{H \rho_{w} w+\varnothing}
$$

where $k_{s g}=$ diffusion-dispersion coefficient of the VOC in the gaseous phase within silage $\left(\mathrm{m}^{2} \mathrm{~s}\right.$ $\left.{ }^{1}\right)$. 
Unlike the analytical solution (Crank, 1975) used by Hafner et al. (2012), we solve the convection-diffusion model through numerical modeling, where Eqs. (1) and (2) are discretized using the finite difference method to achieve a numerical solution (Crank, 1975; Glasgow, 2010). Instead of using high spatial and temporal resolutions commonly required for accurate numerical solutions, a very coarse computational domain and a large fixed time step ( $1 \mathrm{~h})$ are used to minimize computation time. Inaccuracy associated with the use of a coarse resolution was resolved by defining the computational domain as a function of silage characteristics and environmental conditions.

New relationships are used in calculating $H, h_{m}$, and $k_{s g}$. The Henry's law constant $\left(K_{H}\right)$ $\left(\mathrm{mol} \mathrm{kg} \mathrm{atm}^{-1}\right)$ required in estimating $H$ is calculated as:

$$
K_{H}=\frac{1}{P_{s a t} M W_{H_{2} O}}
$$

where $P_{\text {sat }}=$ saturated vapor pressure of a VOC (atm) and $M W_{\mathrm{H}_{2} \mathrm{O}}=$ molecular weight of water $\left(18 \mathrm{~g} \mathrm{~mol}^{-1}\right)$ (Warneck, 2006). The $P_{\text {sat }}$ is calculated as a function of temperature and compoundspecific constants using the Antoine equation (Section 3.3.1 of the supplementary material).

Values for $h_{m}\left(\mathrm{~m} \mathrm{~s}^{-1}\right)$ and $k_{s g}\left(\mathrm{~m}^{2} \mathrm{~s}^{-1}\right)$ for ethanol are determined from friction velocity $\left(u_{*}\right.$, $\mathrm{m} \mathrm{s}^{-1}$, Eqs. (6) and (7), respectively). Details on the derivation of these equations are provided in Section 1.1 of the Supplementary material. The $k_{s g}$ computed with Eq. (7) is adjusted to account for effects of gas-phase and total porosities following the Millington-Quirk model (Hafner et al., 2012). In the absence of experimental data such as those for ethanol (Hafner et al., 2010b; Montes et al., 2010), $h_{m}$ and $k_{s g}$ for other VOCs (e.g., methanol, acids, esters, aldehydes) are calculated using Eqs. (6) and (7), respectively, and then adjusted by the ratio of their $K_{H}$ (Eq. (5)) to that of ethanol to account for relative differences in volatility.

$$
h_{m}=0.0002+0.1625 u_{*}-0.1257 u_{*}^{2}
$$




$$
k_{s g}=\left(0.0256+7.82 u_{*}\right) \times 10^{-4}
$$

To further simplify prediction of VOC emissions, additional assumptions were made.

Changes in silage dry bulk density $\left(\rho_{d r y}, \mathrm{~kg} \mathrm{~m}^{-3}\right)$ and $w$ near the silage face due to silage removal and evaporation, respectively (Robinson et al., 2016), and their potential effects on VOC emissions are neglected. In calculating $\phi$ (Eqs. (3) and (4)), a particle density of $1,600 \mathrm{~kg} \mathrm{~m}^{-3}$ is used for all silage sources (Hafner et al., 2012).

\subsubsection{Computational Domain}

The long computation time associated with numerical modeling (Crank, 1975; Glasgow, 2010) was resolved by implementing a computational domain defined as a function of silage characteristics and environmental conditions. This approach allows the silage VOC emission model to have negligible computation time without sacrificing prediction accuracy. In simulating ethanol emission datasets from Hafner et al. (2010b) and Montes et al. (2010), the performance of this faster silage VOC model provided emissions comparable to the numerical solution obtained using a high resolution domain (see Supplementary material).

Silage storage is represented as a 1-m deep source simulated in 3 layers while the feed lane is a $0.15-\mathrm{m}$ deep source simulated in 2 layers. Depth equations for silage storages are given by:

$$
\begin{gathered}
d_{1}=\left(9.21 \times 10^{-3}-\rho_{d r y}\left(1.47 \times 10^{-5}\right)\right)+1053.6 u_{*} \rho_{d r y}^{-1.668} \\
d_{2}=40.5 u_{*} \rho_{d r y}^{-1.336} \\
d_{3}=1.0-\left(d_{1}+d_{2}\right)
\end{gathered}
$$

where $d_{1}, d_{2}$, and $d_{3}=$ depths for first (surface), second, and third layers, respectively (m). For feed lanes, depth equations are:

$$
d_{1}=\max \left(4.7 \times 10^{-3}, 1.23 \times 10^{-2}-\rho_{d r y}\left(5.87 \times 10^{-5}\right)\right)+
$$




$$
\begin{gathered}
u_{*}\left(1.469-0.263 \ln \rho_{d r y}\right) \\
d_{2}=0.15-d_{1}
\end{gathered}
$$

With these equations, prediction of emission potential primarily depends on the depth of the first simulation layer - the greater this depth (e.g., high $u_{*}$ ) the higher the emission potential. The derivation of these equations is described in Section 1.2 of the Supplementary material. As with $h_{m}$ and $k_{s g}$, these depths are also adjusted to account for the difference of other VOCs relative to ethanol (Section 1.2 of the Supplementary material).

\subsection{Feed Mixing}

With the assumption that all gas-phase VOCs within silage are released into the atmosphere, VOC loss of each type $(\mathrm{g})$ during feed mixing $\left(j_{\text {mixing }}\right)$ is given by:

$$
j_{\text {mixing }}=C_{g} V_{g}
$$

where $C_{g}=$ gas-phase VOC concentration $\left(\mathrm{g} \mathrm{m}^{-3}\right)$, and $V_{g}=$ volume of gas-filled pores within

silage $\left(\mathrm{m}^{3}\right)$. The $C_{g}$ is calculated following Hafner et al. (2012) while $V_{g}$ is just the product of the mixer volume and gas-filled porosity of silage during storage (Section 3.2 of the Supplementary material). Effects of mixing parameters (power, duration) and presence of other TMR components on silage VOC emissions are neglected in the simulation.

Because no measurement was made on VOC losses during feed mixing, we were not able to verify the performance of Eq. (10). Using this model, feed mixing contributed $<1 \%$ of the total VOC emissions from silage, so this appears to be a less important emission source.

\section{Model Evaluation}

The performance of the silage VOC emission model was evaluated using field measurements of ethanol and methanol emitted from several silage sources at a commercial dairy farm in central California (Mitloehner et al., 2016). Measured emission from conventional silage 
piles (CSP) and silage bags (SB) were used in assessing model performance for silage storages. For silage spread out in feed lanes, the model was evaluated using emissions measured from TMR and loose corn silage (LCS) samples. Mean absolute error (MAE), root mean square error (RMSE), and an index of agreement (IA) between measured and simulated emission were used to assess model performance (Willmott et al. 2012) (Section 4 of the Supplementary material).

\subsection{On-Farm Measurement Data}

Measurements of ethanol and methanol emission from corn silage in storage systems (CSP, SB) and feed lanes (TMR, LCS) were collected at the commercial dairy farm from September through October 2014 (Mitloehner et al., 2016). At this dairy, CSP were prepared by compacting freshly chopped, whole-plant corn in drive-over piles using wheel tractors. Chopped corn was packed into SB using a silage bagger (LX1214 Professional Silage Bagger, Ag-Bag, WI). During measurements, CSP and SB had exposed surface areas (i.e., silage faces) of approximately 140 and $12 \mathrm{~m}^{2}$, respectively.

Flux chambers (64.5-L capacity; Odotech Inc., Montreal, Canada) were used in determining emission fluxes from CSP, SB, TMR, and LCS. Description on these flux chambers are provided in Sun et al. (2008). Additionally, a wind tunnel with dimensions of $\sim 0.3 \times 0.8 \times$ $0.13 \mathrm{~m}(\mathrm{~W} \times \mathrm{L} \mathrm{x} \mathrm{H})$ was used in measuring emission from the storages. Concentrations of ethanol and methanol in the headspace above the silage surface were measured with an INNOVA 1412 Photoacoustic Gas Analyzer (LumaSense Technologies Inc., Ballerup, Denmark). Measurement began within 30 min of exposure, and emission fluxes were calculated on an hourly basis. Information on data collected for silage storages and feed samples are summarized in Tables 1 and 2, respectively. Treatments considered in emission measurements were storage type and silage removal (defacing) method for storages (Table 1) and water addition for feed 
samples (Table 2) (Mitloehner et al., 2016). Measurement trials started at 13:00 to14:00 and lasted 13 to $14 \mathrm{~h}$ and 21 to $23 \mathrm{~h}$ for CSP and SB, respectively, (Table 1 ) and 18 to $20 \mathrm{~h}$ for TMR and LCS (Table 2).

Table 1. Details on emission measurements for conventional silage piles (CSP) and silage bags (SB).

\begin{tabular}{|c|c|c|c|c|c|c|}
\hline \multirow[t]{2}{*}{ Storage Type } & \multirow[t]{2}{*}{$\begin{array}{l}\text { Removal } \\
\text { Method }^{\text {a }}\end{array}$} & \multirow[t]{2}{*}{$\begin{array}{l}\text { Replicate } \\
\text { No. }\end{array}$} & \multicolumn{2}{|c|}{ Measurement } & \multicolumn{2}{|c|}{$\begin{array}{l}\text { Initial Concentration } \\
\qquad\left(\mathrm{mg} \mathrm{L}^{-1}\right)^{\mathrm{b}}\end{array}$} \\
\hline & & & Date & $\begin{array}{l}\text { No. of } \\
\text { Hours }\end{array}$ & Ethanol & Methanol \\
\hline \multirow[t]{9}{*}{ CSP } & Lateral & $1^{\mathrm{c}}$ & $09 / 15 / 2014$ & 13 & 253,182 & 26,27 \\
\hline & & 2 & $09 / 17 / 2014$ & 14 & 136 & 24 \\
\hline & & 3 & $09 / 18 / 2014$ & 14 & 219 & 25 \\
\hline & \multirow[t]{3}{*}{ Perpendicular } & $1^{c}$ & $09 / 22 / 2014$ & 13 & 330,194 & 33,27 \\
\hline & & 2 & $09 / 24 / 2014$ & 14 & 436 & 40 \\
\hline & & 3 & $09 / 25 / 2014$ & 14 & 276 & 27 \\
\hline & \multirow[t]{3}{*}{ Rake } & $1^{\mathrm{c}}$ & $10 / 01 / 2014$ & 14 & 389,336 & 38,40 \\
\hline & & 2 & $10 / 02 / 2014$ & 14 & 340 & 32 \\
\hline & & 3 & $10 / 03 / 2014$ & 14 & 293 & 29 \\
\hline \multirow[t]{3}{*}{ SB } & - & $1^{\mathrm{c}}$ & $10 / 23 / 2014$ & 23 & 146,123 & 10,10 \\
\hline & & 2 & $10 / 29 / 2014$ & 21 & 158 & 10 \\
\hline & & 3 & $10 / 30 / 2014$ & 23 & 148 & 9 \\
\hline
\end{tabular}

\footnotetext{
${ }^{a}$ Lateral defacing using front-end loader with silage removal done parallel to the silage face; perpendicular defacing using front-end loader with silage removal done frontal and perpendicular to the silage face; rake defacing using a device leaving a smooth face.

${ }^{\mathrm{b}}$ Gas chromatography-based concentration for $10 \mathrm{~g}$ silage sample $+90 \mathrm{~g}$ water.

${ }^{\mathrm{c}}$ First and second values reported for flux chamber and wind tunnel measurements, respectively.
} 
Table 2. Details on emission measurements for total mixed ration (TMR) and loose corn silage (LCS).

\begin{tabular}{|c|c|c|c|c|c|}
\hline \multirow[t]{2}{*}{ Source } & \multirow[t]{2}{*}{$\begin{array}{l}\text { Water Addition } \\
\text { (\%, wet-basis) }\end{array}$} & \multirow[t]{2}{*}{$\begin{array}{l}\text { Replicate } \\
\text { No. }\end{array}$} & \multirow[t]{2}{*}{ No. of Hours } & \multicolumn{2}{|c|}{$\begin{array}{c}\text { Initial Concentration } \\
\left(\mathrm{mg} \mathrm{L}^{-1}\right)^{\mathrm{b}}\end{array}$} \\
\hline & & & & Ethanol & Methanol \\
\hline \multirow{8}{*}{ TMR } & $0 \%$ & 1 & 18 & 62 & 16 \\
\hline & & 2 & 20 & 177 & 30 \\
\hline & & 3 & 18 & 127 & 18 \\
\hline & $5 \%$ & 1 & 18 & 119 & 18 \\
\hline & & 2 & 18 & 165 & 22 \\
\hline & $10 \%$ & 1 & 18 & 103 & 25 \\
\hline & & 2 & 19 & 186 & 35 \\
\hline & & 3 & 18 & 155 & 24 \\
\hline \multirow[t]{2}{*}{$\mathrm{LCS}^{\mathrm{b}}$} & - & 1 & 18 & 166 & 20 \\
\hline & & 2 & 19 & 145 & 13 \\
\hline
\end{tabular}

${ }^{\mathrm{a}}$ Measurement from 10/08/2014 to $10 / 11 / 2014$.

${ }^{\mathrm{b}}$ Gas chromatography-based concentration for $10 \mathrm{~g}$ silage sample $+90 \mathrm{~g}$ water.

${ }^{\mathrm{c}}$ Added to compare emissions from LCS to those from TMR.

The silage VOC emission model requires several silage properties and environmental parameters. On-farm measurements included the initial ethanol and methanol concentrations in the silage prior to and air temperature above the silage surface during emission measurement. Samples from storages, TMR and LCS were collected for silage characterization. Ethanol and methanol concentrations in the silage were determined using gas chromatography (GC) (Tables 1 and 2). Because moisture contents of silage samples were not determined, concentrations (mg L' ${ }^{1}$ ) reported were for 1:9 mixtures (by weight) of silage samples and water added during GC analyses. Headspace air temperature was monitored using a data logger temperature probe (HOBO, Onset Computer Corporation, MA). Emission measurement and calculation, silage 
preparation and characterization, and GC settings and analyses performed are described in detail by Mitloehner et al. (2016).

\subsection{Simulation Settings}

Because no solid analyses were performed for silage sources evaluated, $\rho_{d r y}$ and $w$ were set in our model evaluation as follows: (a) CSP with parameter estimation through numerical modeling with fine spatial (1 mm) and temporal (1 s) resolution; (b) SB from published or documented values; and (c) TMR was approximated from known sample mass and volume at an assumed moisture content. Parameter estimation through numerical modeling was deemed appropriate in setting the parameters for CSP as the model was able to simulate the more comprehensive data (i.e., with $\rho_{d r y}$ and $w$ ) of Montes et al. (2010) and Hafner et al. (2010b) (Figs. S-3 and S-4). Estimated $\rho_{d r y}$ and $w$ for CSP were within range of those published (Table 3). For SB, $\rho_{d r y}$ and $w$ settings were based on published values (Table 3). For TMR, $\rho_{d r y}$ was estimated from the mass and volume of the sample (0\% water addition) while $w$ was set to $35 \%$ (Table 3) to produce ethanol emission profiles closer to measured. 
Table 3. Dry bulk density and moisture content simulation settings for conventional silage piles (CSP), silage bags (SB), and total mixed ration (TMR).

\begin{tabular}{|c|c|c|c|c|}
\hline \multirow[t]{2}{*}{ Silage Source } & \multirow[t]{2}{*}{ Parameter } & \multirow{2}{*}{$\begin{array}{l}\text { Simulation } \\
\text { Setting }\end{array}$} & \multicolumn{2}{|c|}{ Published Values } \\
\hline & & & Range & Reference \\
\hline \multirow[t]{2}{*}{ CSP } & Dry bulk density $\left(\mathrm{kg} \mathrm{m}^{-3}\right)$ & 240 & $160-320$ & Roach and Kammel (2012) \\
\hline & Moisture (\%, wet-basis) & 60 & $60-70$ & $\begin{array}{l}\text { Silva-del-Rio (2010) } \\
\text { Roach and Kammel (2012) }\end{array}$ \\
\hline \multirow[t]{2}{*}{ SB } & Dry bulk density $\left(\mathrm{kg} \mathrm{m}^{-3}\right)$ & 190 & $65-270$ & $\begin{array}{l}\text { Muck and Holmes (2006) } \\
\text { Ohman et al. (2007) }\end{array}$ \\
\hline & Moisture (\%, wet-basis) & 50 & $40-70$ & $\begin{array}{l}\text { Silva-del-Rio (2010) } \\
\text { Savoie and Jofriet (2003) }\end{array}$ \\
\hline \multirow[t]{2}{*}{ TMR } & Dry bulk density $\left(\mathrm{kg} \mathrm{m}^{-3}\right)$ & $190^{\mathrm{a}}$ & $120-190$ & Buckmaster (2005) \\
\hline & Moisture (\%, wet-basis) & 35 & $40-50$ & Buckmaster (2005) \\
\hline
\end{tabular}

${ }^{\mathrm{a}}$ A lower dry bulk density $\left(120 \mathrm{~kg} \mathrm{~m}^{-3}\right)$ was used for simulating loose corn silage.

The flux chambers and wind tunnel had air flow rates of 1.2 and $5.94 \mathrm{~m}^{3} \mathrm{~h}^{-1}$, respectively (Mitloehner et al., 2016). Based on its dimensions and air flow rate, the wind tunnel had an average air velocity of $0.04 \mathrm{~m} \mathrm{~s}^{-1}$. Using relationships from Deacon (1977; Eq. (14)) and Glasgow (2010; Eq. (5.59)), $u_{*}$ for the wind tunnel was approximately $10 \%$ of its average air velocity. Due to a more complex air flow pattern (Sun et al., 2008), air velocity inside flux chambers was more difficult to estimate. But with its lower air flow setting (20\% of the wind tunnel setting) and larger volume (twice the wind tunnel volume), flux chambers would have an average air velocity and $u_{*}$ lower than those of the wind tunnel. Because the silage computational domain is a function of $u_{*}$, a minimum $u_{*}$ (i.e., $0.002 \mathrm{~m} \mathrm{~s}^{-1}$ ) was implemented for calculation purposes to prevent 0 depth and infinite simulation values.

\subsection{Ethanol and Methanol Emissions from Silage Storages}

Flux chamber-based and simulated ethanol and methanol emission fluxes for CSP with perpendicular defacing are shown in Fig. 1, and with lateral and rake defacing in Figs. S-9 and S- 
10, respectively. Corresponding 12-h emissions (cumulative emissions for the first 12 hours after exposure) are summarized in Table 4.

Measured emission profiles of ethanol and methanol from CSP were similar, such that trials with the highest and lowest ethanol emissions also had the highest and lowest methanol emissions. They were also consistent with trends described by Montes et al. (2010) and Hafner et al. (2010b) with high emission fluxes measured during the first hours of exposure followed by a rapid decline over the succeeding hours. Although air temperature above the silage surface began to decrease starting around 18:00 h, this rapid decline in emission was determined to be caused by the lower VOC content near the surface (Eq. (1)) after the first few hours of exposure rather than the decreasing temperature (i.e., calculation of $P_{\text {sat }}$ and $K_{H}$; Eq. (5)) (data not shown). Trials with the lowest emissions also had the lowest concentrations (Table 1), demonstrating the impact of controlling the amounts of VOCs in silage, such as use of silage additives (Hafner et al., 2014; Weiss and Auerbach, 2015; Weiss et al., 2015a). Still, with trials having the highest emissions but not the highest concentrations, other factors aside from concentrations could further affect VOC emission from silage (Hafner et al., 2010a; Hafner et al., 2012). 


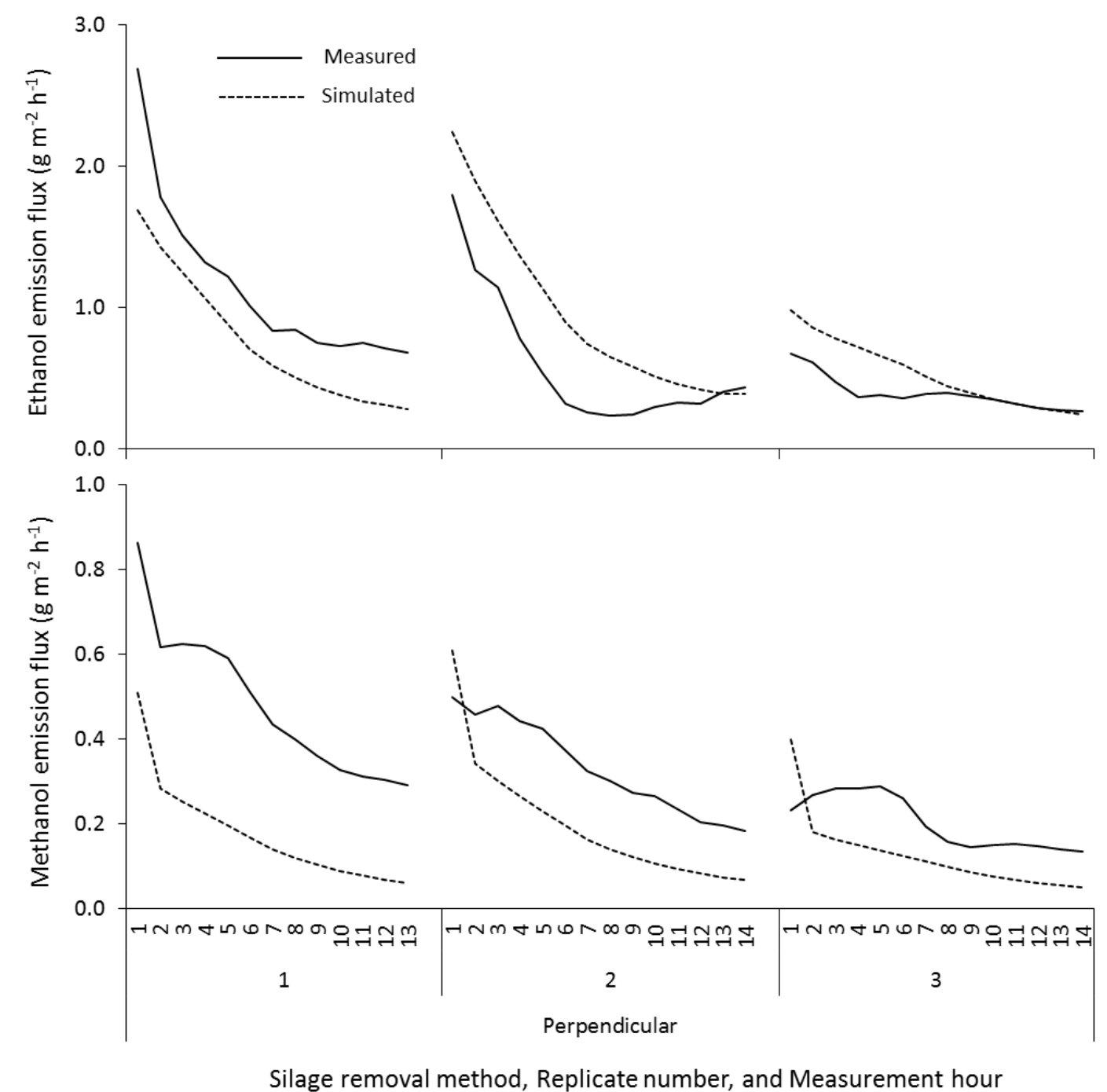

Fig. 1. Simulated and flux chamber-based ethanol (top) and methanol (bottom) emission fluxes for conventional silage piles with perpendicular defacing. 
Table 4. Measured and simulated 12-h emissions of ethanol and methanol for conventional silage piles (CSP) and silage bags (SB). ${ }^{\text {a }}$

\begin{tabular}{|c|c|c|c|c|c|c|c|c|c|c|}
\hline \multirow[t]{3}{*}{ Storage Type } & \multirow{3}{*}{$\begin{array}{l}\text { Removal } \\
\text { Method }^{\text {b }}\end{array}$} & \multirow{3}{*}{$\begin{array}{c}\text { Replicate } \\
\text { No. }\end{array}$} & \multicolumn{4}{|c|}{ Ethanol $\left(\mathrm{g} \mathrm{m}^{-2}\right)$} & \multicolumn{4}{|c|}{ Methanol $\left(\mathrm{g} \mathrm{m}^{-2}\right)$} \\
\hline & & & \multicolumn{2}{|c|}{$\begin{array}{c}\text { Flux } \\
\text { Chamber } \\
\end{array}$} & \multicolumn{2}{|c|}{ Wind Tunnel } & \multicolumn{2}{|c|}{$\begin{array}{c}\text { Flux } \\
\text { Chamber }\end{array}$} & \multicolumn{2}{|c|}{$\begin{array}{c}\text { Wind } \\
\text { Tunnel }\end{array}$} \\
\hline & & & 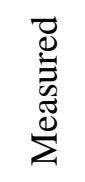 & 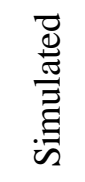 & 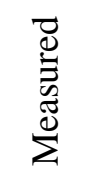 & 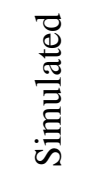 & 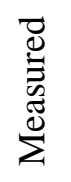 & 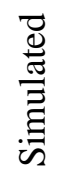 & 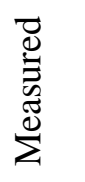 & 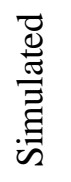 \\
\hline \multirow[t]{9}{*}{ CSP } & Lateral & 1 & 4.9 & 7.9 & 4.6 & 7.1 & 3.8 & 1.8 & 6.0 & 2.1 \\
\hline & & 2 & 5.2 & 4.0 & & & 4.8 & 1.7 & & \\
\hline & & 3 & 3.8 & 6.2 & & & 3.7 & 1.7 & & \\
\hline & Perpendicular & 1 & 14.2 & 9.6 & 16.0 & 7.5 & 6.0 & 2.2 & 10.4 & 1.9 \\
\hline & & 2 & 7.5 & 12.5 & & & 4.3 & 2.7 & & \\
\hline & & 3 & 5.0 & 6.9 & & & 2.6 & 1.7 & & \\
\hline & Rake & 1 & 6.6 & 10.5 & 12.0 & 11.7 & 4.6 & 2.4 & 12.0 & 2.9 \\
\hline & & 2 & 10.5 & 9.5 & & & 4.7 & 2.1 & & \\
\hline & & 3 & 10.4 & 8.7 & & & 4.8 & 2.0 & & \\
\hline \multirow[t]{3}{*}{ SB } & - & 1 & 13.6 & 5.4 & 23.5 & 5.7 & 1.4 & 1.3 & 4.6 & 0.7 \\
\hline & & 2 & 14.4 & 5.9 & & & 1.8 & 1.3 & & \\
\hline & & 3 & 10.7 & 5.4 & & & 3.3 & 1.2 & & \\
\hline \multirow[t]{4}{*}{ CSP } & & Mean & $\overline{c 7.6}$ & 8.4 & 10.9 & 8.8 & 4.4 & 2.0 & 9.5 & 2.3 \\
\hline & & MAE & \multicolumn{2}{|c|}{2.8} & \multicolumn{2}{|c|}{3.7} & \multicolumn{2}{|c|}{2.3} & \multicolumn{2}{|c|}{7.2} \\
\hline & & RMSE & \multicolumn{2}{|c|}{3.1} & \multicolumn{2}{|c|}{5.1} & \multicolumn{2}{|c|}{2.5} & \multicolumn{2}{|c|}{7.5} \\
\hline & & IA & \multicolumn{2}{|c|}{$64 \%$} & \multicolumn{2}{|c|}{$55 \%$} & \multicolumn{2}{|c|}{$37 \%$} & \multicolumn{2}{|c|}{$37 \%$} \\
\hline \multirow[t]{4}{*}{ SB } & & Mean & 12.9 & 5.5 & & & 2.2 & 0.7 & & \\
\hline & & MAE & \multicolumn{2}{|c|}{7.4} & \multicolumn{2}{|c|}{ - } & \multicolumn{2}{|c|}{1.5} & \multicolumn{2}{|c|}{-} \\
\hline & & RMSE & \multicolumn{2}{|c|}{7.5} & \multicolumn{2}{|c|}{ - } & \multicolumn{2}{|c|}{1.7} & & \\
\hline & & IA & & & & & & & & \\
\hline
\end{tabular}

\footnotetext{
${ }^{a} \mathrm{MAE}$ is the mean absolute error, RMSE is the root mean square error, and IA is the index of agreement. Statistical analyses between measured and simulated emissions performed using $12-\mathrm{h}$ cumulative emission.

${ }^{\mathrm{b}}$ Lateral defacing using front-end loader with silage removal done parallel to the silage face; perpendicular defacing using front-end loader with silage removal done frontal and perpendicular to the silage face; rake defacing using a device leaving a smooth face.
} 
The silage VOC model performed well in simulating ethanol emissions measured by flux chambers from CSP (Figs. 1, S-9 and S-10). Based on 12-h totals (Table 4), simulated ethanol emissions agreed well with those measured (IA of 64\%) with MAE and RSME of 2.8 and $3.1 \mathrm{~g}$ $\mathrm{m}^{-2}$, respectively. Using hourly emission fluxes (Fig. 1), agreement between simulated and measured ranged from $61 \%$ to $95 \%$. In contrast, the performance of the model was lower in predicting methanol emission fluxes (IA of $37 \%$ and $44 \%$ to $73 \%$ based on 12 -h and hourly emission fluxes, respectively) as considerably lower methanol emission fluxes were modeled for periods after the first hour of exposure (Figs. 1, S-9 and S-10). This underprediction of methanol emission was due to the approximation of $k_{s g}$ using the equation developed for ethanol (Eq. (7)) (see Section 1.2 of the Supplementary material).

Wind tunnel and simulated emission fluxes for CSP are shown in Fig. 2 and their 12-h emissions are summarized in Table 4. Unlike flux chambers (Fig. 1), emission fluxes measured by the wind tunnel fluctuated through time with measured ethanol and methanol emission fluxes fluctuating simultaneously (Fig. 2). Although not determined, one condition that could have caused these fluctuations would be variations in the wind tunnel air flow. 


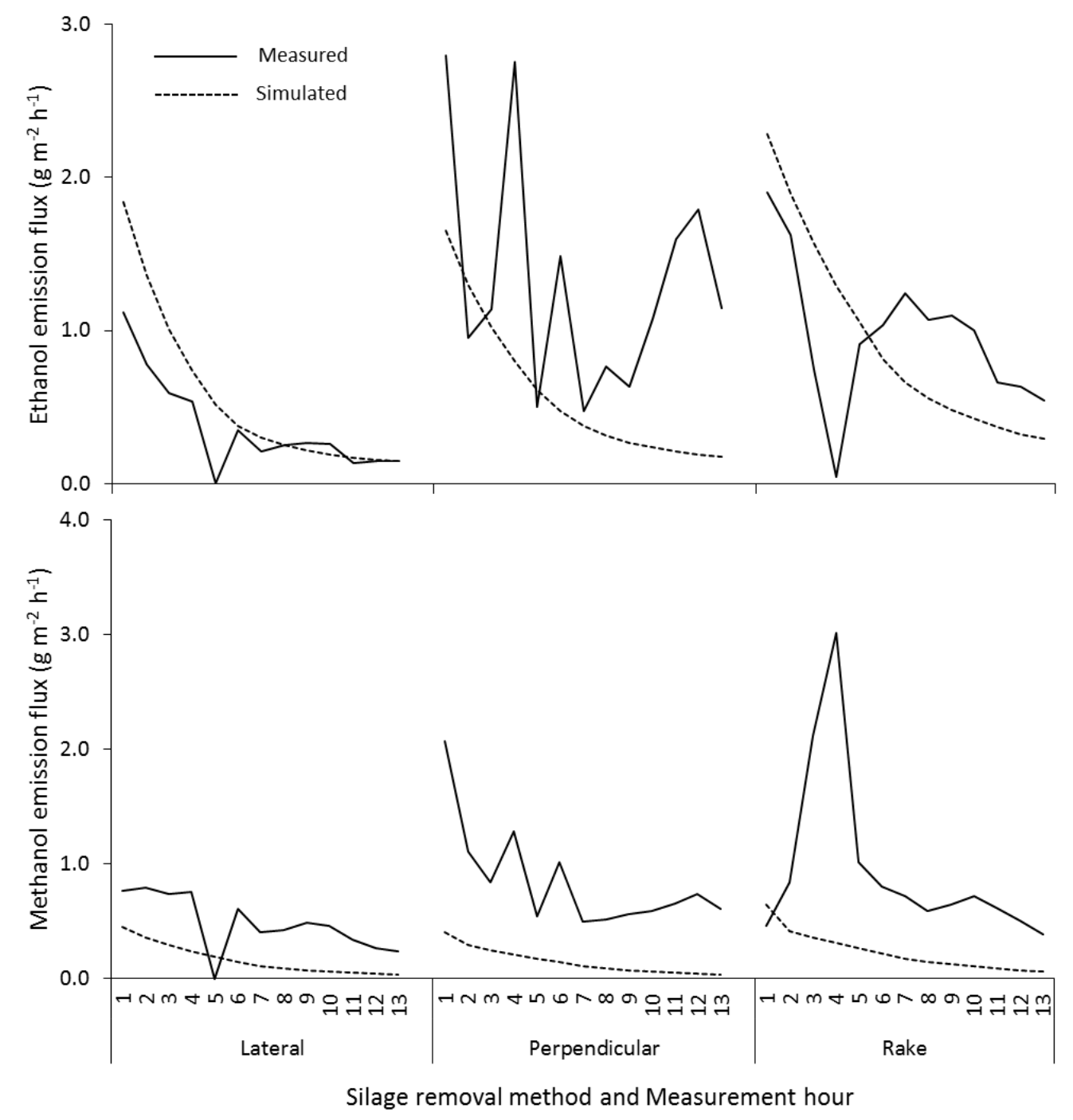

Fig. 2. Simulated and wind tunnel-based ethanol (top) and methanol (bottom) emission fluxes for conventional silage piles.

With air flow and $w$ assumed constant, fluctuations in emissions measured by the wind tunnel could not be predicted. Still, performance in simulating wind tunnel-based emissions was comparable to that for flux chamber-based emissions as the model worked better in predicting emission fluxes of ethanol (IA of 55\%) than methanol (IA of 37\%). The low simulated profile previously described when simulating methanol emissions for flux chambers (Fig. 1) was also obtained for the wind tunnel (Fig. 2). 
Emission fluxes measured by flux chambers and the wind tunnel from SB, together with corresponding simulated fluxes, are plotted in Figs. 3 and 4, respectively. Emission profiles measured from SB were comparable to those from CSP (Figs. 1 and 2). Similarly, the low performance of the model in predicting methanol emissions for SB was due to approximation of $k_{s g}$. Unlike for CSP, however, simulated ethanol emission fluxes for SB did not compare well with measured (IA of $28 \%$ based on 12-h emissions) as emission fluxes modeled for periods after the first hour of exposure were too low (Figs. 3 and 4). This was attributed to the drastic decrease in ethanol content simulated for the defined surface layer (Eq. (8a)) within the first few hours of exposure.

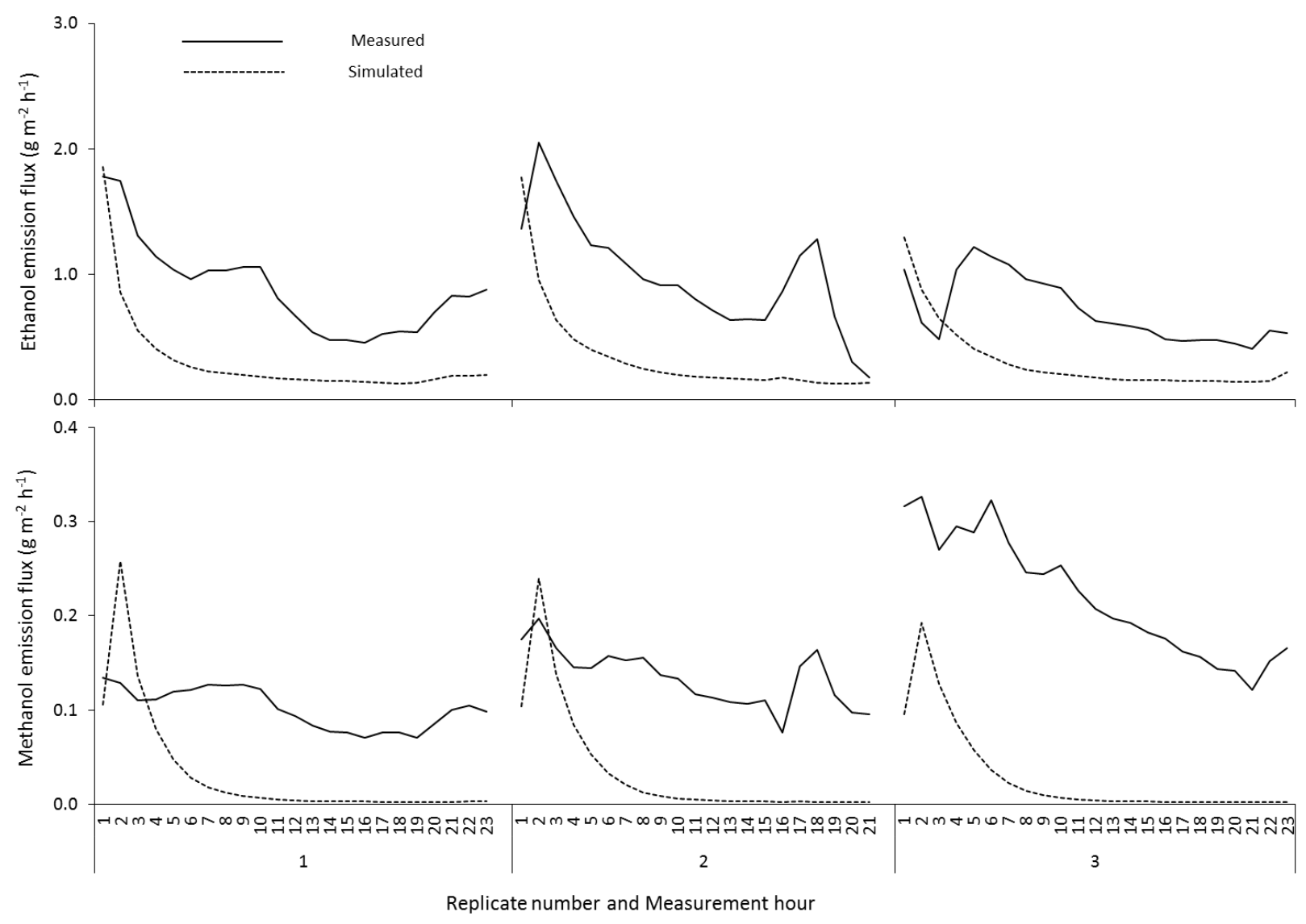

Fig. 3. Simulated and flux chamber-based ethanol (top) and methanol (bottom) emission fluxes for silage bags. 


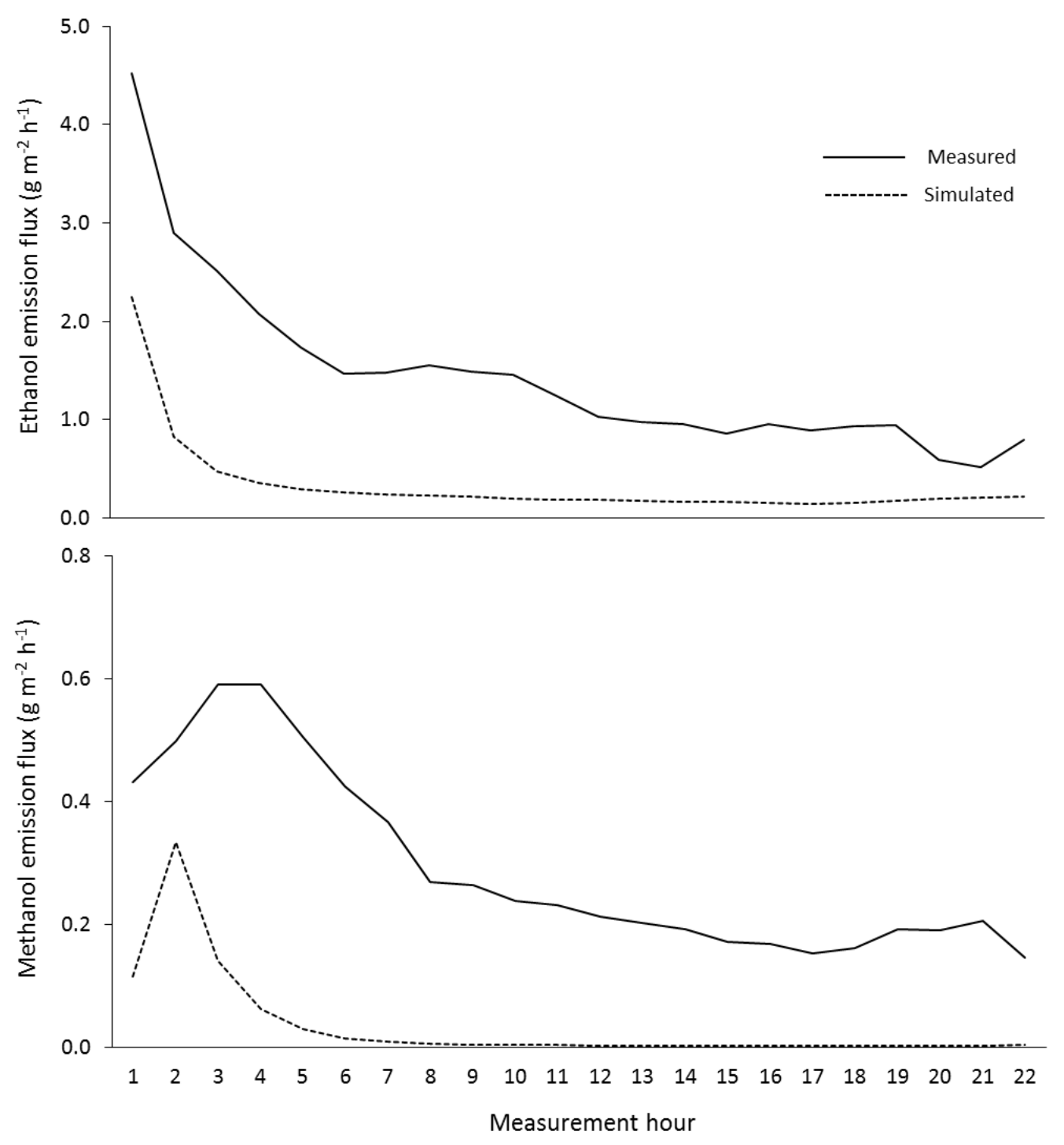

Fig. 4. Simulated and wind tunnel-based ethanol (top) and methanol (bottom) emission fluxes for silage bags.

As illustrated in Fig. 5, SB emitted more VOC per unit area of exposed silage face than CSP. The model, however, was not able to simulate this difference in emission potential between CSP and SB. For flux chambers (i.e., negligible air velocity), prediction of emission was largely influenced by the initial concentration regardless of storage type. This limitation in simulating emissions, particularly for SB, could be attributed to the transport coefficient equations used and/or the assumption of constant silage face conditions. Simulation of SB could be enhanced 
by: (a) higher $k_{s g}$ (i.e., more VOC transferred from lower layers); (b) lower $\rho_{d r y}$ at the surface layer (i.e., loosening due to silage removal); and/or (c) lower $w$ at the surface layer (i.e., increased evaporation due to a loose silage face). Specific reasons behind this low model performance for SB could not be identified at this time as silage characteristics (i.e., $\rho_{d r y}, w$ ) were not measured.

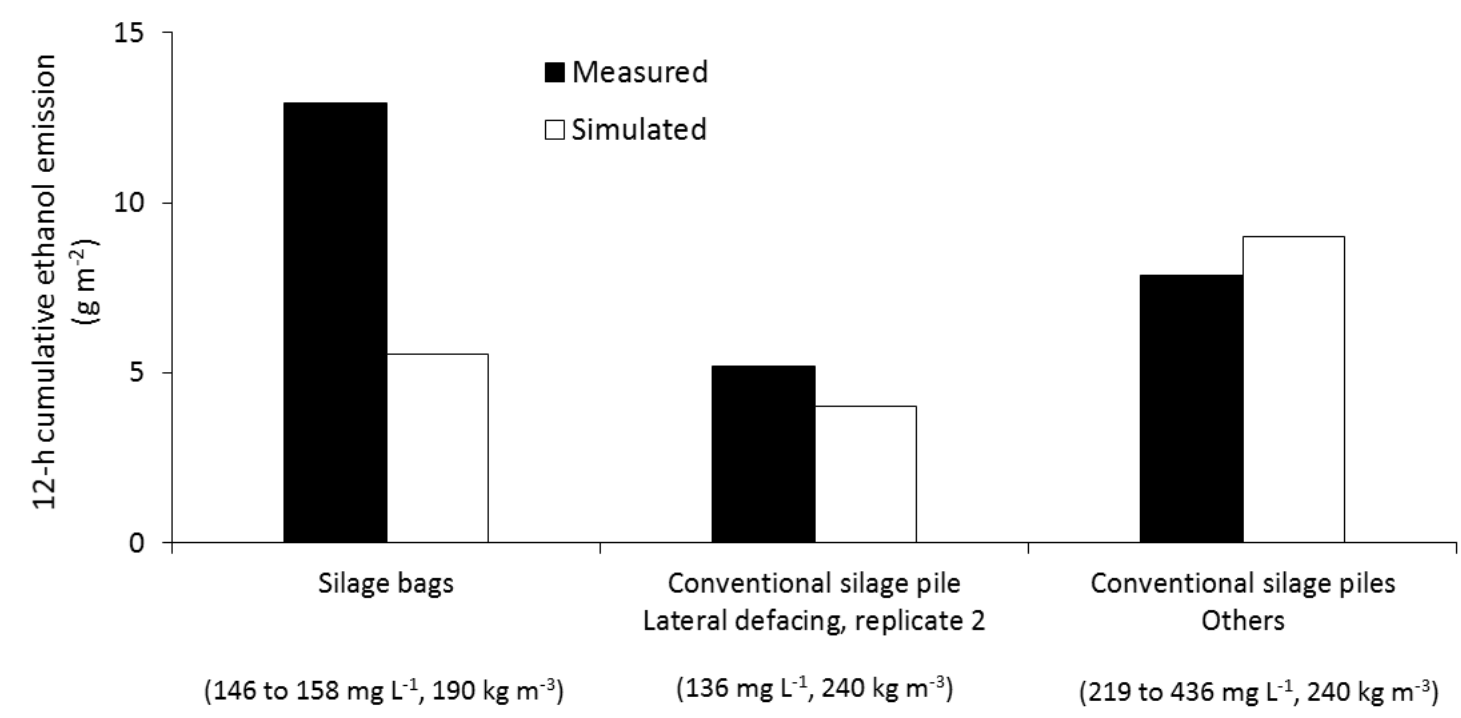

Fig. 5. Simulated and measured (flux chamber) 12-h cumulative ethanol emission for silage storages.

\subsection{Ethanol and Methanol Emissions from Feed Lanes}

Simulated and measured emission fluxes for TMR and LCS are shown in Figs. 6, S-11, S-12, and S-13, with their corresponding cumulative 12-h values summarized in Table 5. Trends of measured emission profiles from TMR and LCS were comparable to those from silage storages. The model worked well in predicting ethanol emission fluxes from both TMR and LCS throughout the measurement period (Figs. 6, S-11, S-12, and S-13), with IA of 53\% and $67 \%$ to 98\% based on 12-h emissions (Table 5) and hourly emission fluxes (Fig. 6), respectively. 
Loose corn silage was excluded in assessing performance in simulating methanol emissions because of measurement uncertainty, i.e., cumulative methanol emission (Table 5) greatly exceeded the initial mass in the silage (Table 2). For TMR (e.g., Fig. 6), the model overpredicted methanol emission fluxes, in contrast to its performance for silage storages where underprediction of methanol emissions occurred. With an agreement of only $36 \%$, the simulated 12-h emission (2.3 $\left.\mathrm{g} \mathrm{m}^{-2}\right)$ was twice the corresponding measured value $\left(1.1 \mathrm{~g} \mathrm{~m}^{-2}\right)$ (Table 5). Agreement between measured and simulated hourly methanol emission fluxes ranged from 5\% to $60 \%$ only because the model simulated higher emissions for the first few hours of exposure (Fig. 6). Further analyses and comparison of emission potentials among the silage sources evaluated (CSP, SB, TMR/LCS) indicated that uncertainties in measured emissions (Table 5) and/or concentrations (Table 2) could have caused the large discrepancy obtained between measured and simulated methanol emissions for TMR. Because of TMR's loose structure and methanol's high volatility, significant amounts of methanol might have emitted during sample collection and set-up prior to measurement which led to lower methanol emissions measured. 

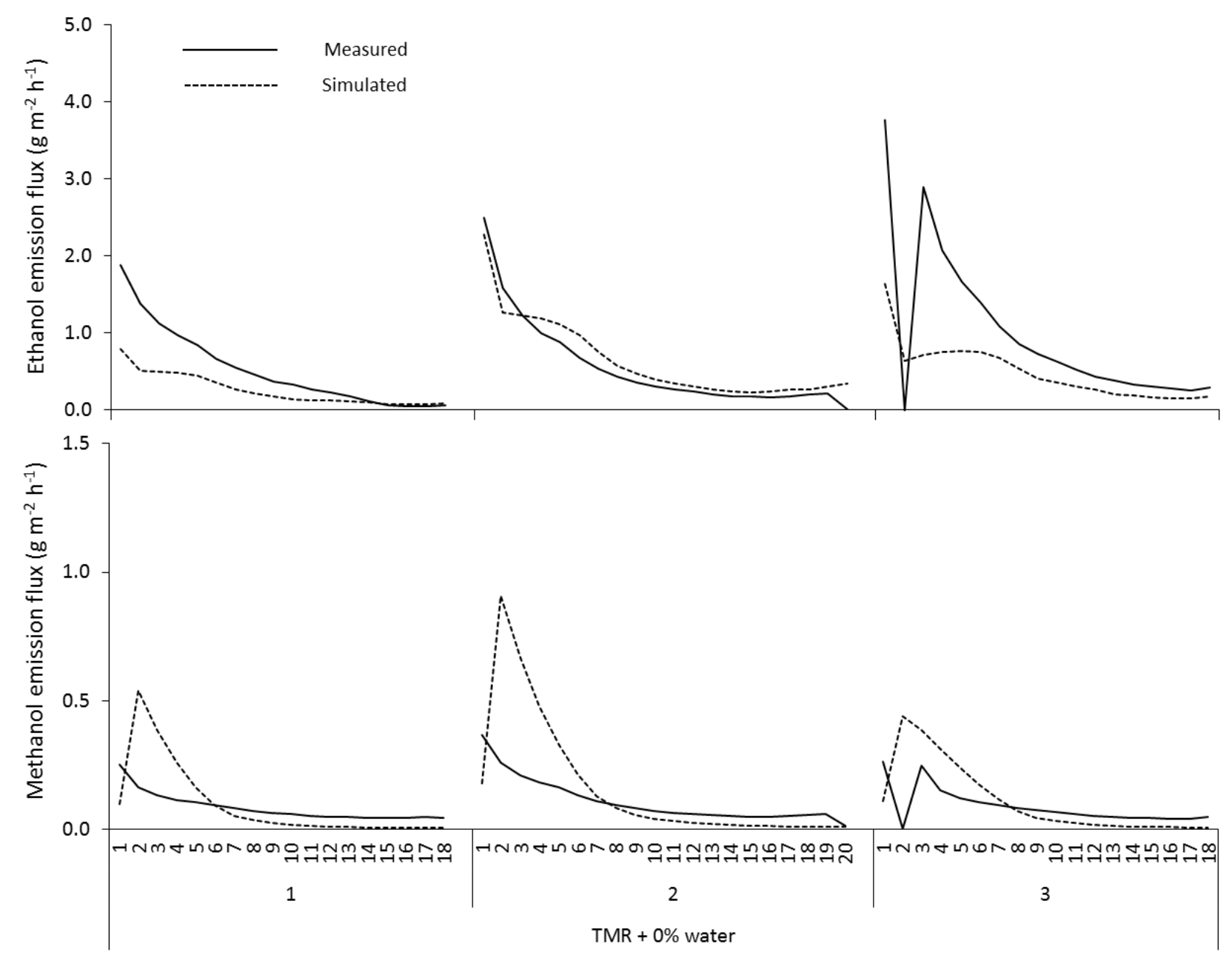

Sample, Replicate number, and Measurement hour

Fig. 6. Simulated and measured (flux chamber) ethanol (top) and methanol (bottom) emission fluxes for a total mixed ration (TMR) without water addition. 
Table 5. Measured and simulated 12-h emissions of ethanol and methanol for total mixed ration (TMR) and loose corn silage (LCS). ${ }^{a}$

\begin{tabular}{|c|c|c|c|c|c|c|}
\hline \multirow[t]{2}{*}{ Source } & \multirow[t]{2}{*}{$\begin{array}{c}\text { Water } \\
\text { Addition }\end{array}$} & \multirow[t]{2}{*}{$\begin{array}{c}\text { Replicate } \\
\text { No. }\end{array}$} & \multicolumn{2}{|c|}{$\begin{array}{c}\text { Ethanol } \\
\left(\mathrm{g} \mathrm{m}^{-2}\right)\end{array}$} & \multicolumn{2}{|c|}{$\begin{array}{c}\text { Methanol } \\
\left(\mathrm{g} \mathrm{m}^{-2}\right)\end{array}$} \\
\hline & & & Measured & Simulated & Measured & Simulated \\
\hline \multirow[t]{8}{*}{ TMR } & $0 \%$ & 1 & 99.1 & 4.1 & 101.2 & $\begin{array}{l}1.7 \\
\end{array}$ \\
\hline & & 2 & 10.0 & 10.9 & 1.8 & 3.1 \\
\hline & & 3 & 16.1 & 7.8 & 1.3 & 2.0 \\
\hline & $5 \%$ & 1 & 4.3 & 6.7 & 0.6 & 1.9 \\
\hline & & 2 & 9.5 & 8.4 & 0.8 & 2.2 \\
\hline & $10 \%$ & 1 & 3.4 & 4.8 & 0.6 & 2.4 \\
\hline & & 2 & 7.4 & 7.8 & 1.1 & 3.1 \\
\hline & & 3 & 10.8 & 6.4 & 0.9 & 2.1 \\
\hline \multirow[t]{2}{*}{ LCS } & - & 1 & 6.9 & 11.4 & 4.9 & 1.4 \\
\hline & & 2 & 12.6 & 9.8 & 7.3 & 0.9 \\
\hline \multirow[t]{4}{*}{ All data } & & Mean & 9.0 & 7.8 & 1.1 & 2.3 \\
\hline & & MAE & \multicolumn{2}{|c|}{3.1} & \multicolumn{2}{|c|}{1.3} \\
\hline & & RMSE & \multicolumn{2}{|c|}{3.9} & \multicolumn{2}{|c|}{1.3} \\
\hline & & IA & \multicolumn{2}{|c|}{$53 \%$} & \multicolumn{2}{|c|}{$36 \%$} \\
\hline
\end{tabular}

\footnotetext{
${ }^{\mathrm{a}} \mathrm{MAE}$ is the mean absolute error, RMSE is the root mean square error, and IA is the index of agreement. Statistical analyses between measured and simulated emissions performed using 12-h emission fluxes.

${ }^{\mathrm{b}}$ Statistical analyses excluded LCS.
}

\section{Model Application in Whole-Farm Analyses}

The silage VOC emission model is incorporated as a component of our whole-farm simulation model. Integrated in IFSM, the silage VOC emission model can be used to evaluate the effects of silage management on the overall performance, economics, and environmental impacts of farm production systems. To demonstrate its application in whole-farm analyses, the model was used to assess and compare VOC emissions as influenced by various management 
strategies for silage storage and feeding on a representative California dairy farm. Despite the uncertainty remaining in model predictions, it still provides a valuable tool for comparing management options. Although accuracy of predicted emissions cannot be confirmed for all VOCs, the relative differences created through management and environmental changes should reflect the impact of mitigation strategies.

\subsection{Integrated Farm System Model}

The IFSM simulates crop production, feed use, and the return of manure nutrients back to the land for many years of daily weather on crop, dairy, or beef producing farms (Rotz et al., 2016). Nutrient flows are tracked to predict losses to the environment and potential accumulation in the soil. Losses include greenhouse gas emissions, ammonia volatilization, denitrification and leaching losses of nitrogen, and erosion of sediment and runoff of sediment-bound and dissolved nitrogen and phosphorus across the farm boundaries. A cradle-to-farm gate life cycle assessment determines annual carbon, energy, water, and reactive nitrogen footprints of the farm products produced. Simulated performance is used to determine production costs, incomes, and economic return for each year of weather. The distribution of annual values can be used to evaluate the risk or variance due to the variation in daily and annual weather patterns.

The silage VOC emission model gives IFSM the ability to evaluate management effects on VOC emissions along with other aspects of farm performance, environmental impact and economics. To represent total VOC emission, four groups of VOCs that have the most potential to contribute to poor air quality are considered: acids, alcohols, esters, and aldehydes (Hafner et al., 2013). On farms, VOC emission from silage is determined by the production of VOCs in silage and the amount of each compound that is volatilized. Production of VOCs can vary greatly among silages, and sources of this variability are not yet known (Hafner et al., 2013). Therefore, 
VOC production is set as an initial concentration based on typical values for different types of silage (Table S-1). From these fixed initial concentrations, emission losses are predicted and the remaining VOC mass is tracked as silage moves through three stages: removal from storage, feed mixing, and feeding (Hafner et al., 2010a) (see Fig. S-14 of Supplementary material). Emissions during initial filling, fermentation and storage phases of silage management are not included. Emissions during these phases have not been measured and they are assumed to be small and unimportant compared to those from the silage face and feeding of the silage. The VOC emission following defacing and during mixing reduces the concentration of VOCs present during feeding (Section 3.1.1 of the Supplementary material). Calculated emissions from each group of compounds are aggregated after normalizing emissions based on the ozone formation potential of each group. The normalized emission of a VOC group is the product of the predicted emission (kg VOC) and corresponding Equal Benefit Incremental Reactivity ( $\mathrm{kg} \mathrm{O}_{3}$ per $\mathrm{kg}$ VOC) (Carter, 2009) (Table S-3). In the model, each VOC group is represented by a single compound: acetic acid for acids, ethanol for alcohols, ethyl acetate for esters, and acetaldehyde for aldehydes (Hafner et al., 2012; Hafner et al., 2013).

For completeness, VOC emissions are also predicted from manure sources in the housing facility, during storage and following field application (Rotz et al., 2016). A similar approach as that for silage is used to estimate manure VOC emissions where an initial concentration is assumed and losses are predicted using theoretical relationships of mass transfer. Unlike silage, manure sources are treated as a single layer with a uniform VOC concentration and convection loss is simulated from the surface. Total VOCs tracked are divided into 5 groups (C2 and C3 acids, $\mathrm{C} 4$ and larger acids, alcohols, aromatic acids and aromatics) represented in the simulation by acetic acid, butyric acid, ethanol, phenyl-acetic and indole, respectively. This portion of the 
model has not been evaluated with farm data so the accuracy of these estimates are unknown.

Still, we include these predictions in our simulations to indicate how changes in silage emissions affect whole farm emissions. In general, reactive VOC emissions from manure are relatively small compared to those from silage (Chung et al., 2010). Our whole-farm estimated emissions do not include enteric emissions from the animals other than methane. There are likely other compounds emitted by the animals, but little data exist to support a model of this source. This source is also expected to be relatively small compared to silage and manure sources.

\subsection{Farm Description}

A farm representing a well-managed dairy production system in central California was simulated. The farm included 2,000 Holstein cows and 1,650 replacement heifers on 300 ha of clay loam soil. Crops produced were corn silage followed by oat silage in a double crop production system. Irrigation was used as needed with up to 60 and $20 \mathrm{~cm}$ applied annually to corn and the winter oat crop, respectively. Corn silage harvest was initiated around September 1 and oat silage was harvested in the spring beginning April 20. Corn and oat silages were preserved in covered conventional piles.

Annual milk production was $11,000 \mathrm{~kg} \mathrm{cow}^{-1}$ corrected to $4 \%$ fat and $3.3 \%$ protein. All animals were fed TMRs, comprised of farm-produced silage supplemented with purchased alfalfa hay, corn grain, and high protein feed mixes to meet energy, protein, and mineral requirements. Animals had access to feed throughout the day. All animals were housed in free stall barns with access to open lots. Manure from free stall floors was flushed daily and handled as a liquid slurry, which was stored in a lined earthen basin for up to 6 months, while manure from the lots was handled dry. All manure was used to fertilize the cropland, with $70 \%$ applied to the corn crop. Nitrogen fertilizer was applied to corn at a rate of $100 \mathrm{~kg} \mathrm{ha}^{-1}$. All other crop 
nutrient needs were met through manure application. The farm was simulated over 25 years of historical weather for Sacramento (1981 to 2005).

\subsection{Silage Management and VOC Emissions}

For a base scenario, the farm was simulated with a silage pile defaced using a bucketequipped front-end loader with a defacing-feeding frequency of once per day. Based on the silage pile measured in this study, the conventional pile had a $140-\mathrm{m}^{2}$ silage face. The simulation predicted that the farm had more than $8,000 \mathrm{~kg}$ of reactive VOCs emitted annually from piles and around 20,000 kg emitted during feeding (i.e., feed mixing + silage lying in the feed lane) (Table 6). Almost all of the feeding loss (>99\%) occurred from the feed lane. The main driver for this relatively large loss during feeding was the large exposed area of the feed. Total feed area simulated for the farm was more than $2,000 \mathrm{~m}^{2}$ at the start of feeding (i.e., approximately $0.5 \mathrm{~m}^{2}$ per animal), which was over 16 times that of the silage face. Therefore, even if emission rates per unit of exposed area predicted for the feed lane were just a third of those for piles, much greater emission occurred from the feed lane. These simulated results for feed lanes (i.e., lower emission fluxes but higher total emissions than silage storages) are in agreement with findings by Alanis et al. (2008) and Chung et al. (2010). An additional 8,000 $\mathrm{kg}$ of reactive VOC was predicted to be emitted from manure sources, which was about $28 \%$ of that emitted from silage.

Effects of management options for silage storage are summarized in (Table 6). Compared to a conventional pile, a bunker silo has side walls allowing some increase in density during packing and less dry matter loss during storage. This change, however, had little effect on simulated emissions (Table 6). Although it led to a slightly higher loss during feeding (5\% increase), use of silage bags greatly reduced reactive VOC emissions from silage (23\% decrease) and the whole farm (18\% decrease) due to a much smaller exposed area $\left(12 \mathrm{~m}^{2}\right)$ resulting in a 
90\% decrease in losses from the silage face (Table 6). It should be noted, however, that the model may underpredict emissions from silage bags by more than half, as indicated in Table 4 .

Table 6. Effect of various silage storage and feeding practices on the annual potential ozone forming VOC emissions from a hypothetical representative California dairy farm. ${ }^{\mathrm{a}, \mathrm{b}}$

\begin{tabular}{|c|c|c|c|c|c|c|c|}
\hline \multicolumn{2}{|c|}{ Silage management } & \multirow{2}{*}{$\begin{array}{c}\text { Silage } \\
\text { face }(\mathrm{kg} \\
\left.\mathrm{O}_{3}\right)\end{array}$} & \multirow{2}{*}{$\begin{array}{c}\text { Feeding }^{\mathrm{c}} \\
\left(\mathrm{kg} \mathrm{O}_{3}\right)\end{array}$} & \multicolumn{2}{|c|}{ Total silage loss } & \multicolumn{2}{|c|}{ Total farm loss ${ }^{\mathrm{d}}$} \\
\hline & & & & $\left(\mathrm{kg} \mathrm{O}_{3}\right)$ & $\begin{array}{c}\% \\
\text { change }^{\mathrm{e}}\end{array}$ & $\left(\mathrm{kg} \mathrm{O}_{3}\right)$ & $\begin{array}{c}\% \\
\text { change }\end{array}$ \\
\hline Storage & Conv. pile & 8,579 & 20,604 & 29,183 & & 37,365 & \\
\hline \multirow[t]{2}{*}{ type } & Bunker & 7,531 & 20,737 & 28,268 & -3.1 & 36,461 & -2.4 \\
\hline & Bag & 760 & 21,737 & 22,497 & -22.9 & 30,652 & -18.0 \\
\hline Pack & Light tractor & 10,587 & 20,333 & 30,920 & & 39,100 & \\
\hline density & Heavy tractor & 8,579 & 20,604 & 29,183 & -5.6 & 37,365 & -4.4 \\
\hline Silage & Bucket & 8,579 & 20,604 & 29,183 & & 37,365 & \\
\hline unloader & Defacer & 7,834 & 20,639 & 28,473 & -2.4 & 36,655 & -1.9 \\
\hline Feeding & Dry lot corral & 8,591 & 35,368 & 43,959 & & 52,525 & \\
\hline \multirow[t]{2}{*}{ site } & Free stall barn & 8,579 & 20,604 & 29,183 & -33.6 & 37,365 & -28.9 \\
\hline & Enclosed barn & 8,579 & 21,232 & 29,811 & -32.2 & 37,505 & -28.6 \\
\hline Feeding & $1 \mathrm{x} \mathrm{d}^{-1}$ & 8,579 & 20,604 & 29,183 & & 37,365 & \\
\hline \multirow[t]{3}{*}{ frequency } & $2 \mathrm{x} \mathrm{d}^{-1}$ & 10,346 & 14,921 & 25,267 & -13.4 & 33,450 & -10.5 \\
\hline & $3 \mathrm{xd}^{-1}$ & 11,458 & 11,989 & 23,447 & -19.7 & 31,629 & -15.4 \\
\hline & $4 \mathrm{x} \mathrm{d}^{-1}$ & 12,319 & 10,073 & 22,392 & -23.3 & 38,249 & -18.2 \\
\hline \multirow[t]{2}{*}{ Climate } & Central CA & 8,579 & 20,604 & 29,183 & & 37,365 & \\
\hline & Southern ID & 2,876 & 15,007 & 17,883 & -38.7 & 25,066 & -32.9 \\
\hline
\end{tabular}

${ }^{a}$ Total VOC emissions are converted to their potential to form ozone based upon their reactivity (Equal Benefit Incremental Reactivity; Carter, 2009).

${ }^{\mathrm{b}}$ The representative farm had 2,000 cows plus 1,650 replacement heifers with 300 ha of double cropped corn and small grain harvested, stored and fed as silage.

${ }^{\mathrm{c}}$ Loss from silage during feed mixing and while lying in the feed lane.

${ }^{\mathrm{d}}$ Total farm loss includes predicted losses from manure during housing, storage, and field application.

${ }^{\mathrm{e}}$ Percent change is computed as 100 times the difference between emissions from the alternative option and the base option divided by the base option emission. The base option for each silage management are the conventional pile, light tractor, bucket unloader, dry lot corral, $1 \mathrm{x} \mathrm{d}^{-1}$ feeding frequency, and central California, respectively. 
Our simulation indicates that changes in the pack density of silage stored in conventional piles have a relatively small effect on VOC emissions. A $15 \%$ increase in density through the use of a heavier packing tractor led to a $20 \%$ decrease in emissions from the silage face. This resulted in an overall decrease in emission of just $4 \%$ as the silage face contributed only $23 \%$ of the total VOC emissions from the whole farm (Table 6). With effects of silage density on VOC production not well understood, our model assumes that the initial concentrations of VOC compounds in the silage are similar regardless of density. This may not be the case in reality as pack density should influence silage fermentation and resulting VOC concentrations. Weiss et al. (2015b) reported higher concentrations for several alcohols (e.g., ethanol, n-propanol) and esters (e.g., ethyl acetate, ethyl lactate, propyl acetate) in silages stored with better packing. Similarly, our measurement shows higher ethanol and methanol concentrations for conventional piles (Table 1), which typically have better packing than bags (Table 3). This greater concentration could lead to greater emissions.

The technology referred to as a silage rake provides a smoother and denser silage face during defacing. In the model, an increase in effective area of the silage face due to surface roughness was set to $37 \%$ for the bucket unloader and $8 \%$ for the rake (Muck and Rotz, 1996). Simulation showed that use of a silage rake provided a $9 \%$ decrease in loss from the face of the pile but only an overall $2 \%$ decrease from the whole farm (Table 6). Although this defacing technology may provide substantial reductions of emissions from the silage face, model predictions indicate relatively low benefit from a whole farm perspective.

Feeding management, which includes feeding site (i.e., cow housing) and feed delivery, may have the greatest impact on silage VOC emissions (Table 6). Our simulations indicate that feeding cows in an open feed lane on an open dry lot can greatly increase reactive VOC 
emissions compared to an open, naturally ventilated (i.e., roofed but without side walls) free stall barn or an enclosed free stall barn that is mechanically ventilated. The cause of this great difference is primarily the velocity of air moving over the feed (Section 3.1.2 of the Supplementary material). Compared to feeding on an open lot, there was a $40 \%$ decrease in reactive VOC emissions when feeding cows inside a barn (Table 6). To our knowledge, on-farm measurements are not available to evaluate predictions for emissions across housing/feeding systems. The few studies that measured silage VOC emissions on-farm used flux chambers operated at a very low flow rate (i.e., negligible air velocity) (Alanis et al., 2008; Chung et al., 2010). With a mass balance approach, Hafner et al. (2012) estimated silage VOC losses under actual barn conditions; however, response of VOC emissions to air flow was not established as measured parameters were limited. Comprehensive measurements at actual barn conditions must therefore be made before recommendations on feeding strategies can be made. Nevertheless, model predictions indicate that changes in feed bunk design to limit air flow over the feed could perhaps provide the greatest benefit in reducing VOC emissions from dairy and beef farms where silage is fed and this may be achieved with relatively small cost to the producer.

Based on our simulations, increasing the number of feedings per day can reduce overall reactive VOC emissions from silage and the whole farm. At higher feeding frequency, lower amounts of feed are delivered to the cows per feeding, resulting in smaller exposed areas for emissions. Although emissions from the silage face increased by $40 \%$ due to more frequent defacing, 4 feedings per day reduced VOC emissions from the feed lane by almost half, and overall VOC emissions from silage and the whole farm by $23 \%$ and $18 \%$, respectively (Table 6).

Climate can also have a major effect on reactive VOC emissions from silage. By simulating the same dairy farm in the climate of southern Idaho, emissions from silage sources 
were reduced by $39 \%$ (Table 6 ). This effect is influenced primarily by lower ambient

temperatures where the average annual temperature in Idaho was $5^{\circ} \mathrm{C}$ less than that in California. Wind speed also averaged about $15 \%$ less in Idaho.

Aside from the climate and silage management strategies considered (Table 6), it is worth mentioning the potential of silage additives on reducing VOC emissions. As observed from onfarm measurements (Tables 1 and 4), lowest emissions from CSP were observed for those with the lowest concentrations. Based on several studies (Hafner et al., 2014; Weiss and Auerbach, 2015; Weiss et al., 2015a), chemical additives for silage such as potassium sorbate were shown to reduce concentrations of several VOCs, which included ethanol, ethyl acetate and ethyl lactate, by more than $50 \%$. In the model, predicted emission for a VOC is proportional to its concentration within silage (Eqs. (1) and (2)). Further research is needed to determine additive treatment effects on VOC concentrations and emissions.

\section{Conclusion}

A silage VOC emission model was developed for use in whole farm simulation, and the model was evaluated using ethanol and methanol emission measurements from a commercial dairy farm in California. Overall, the model appropriately predicted ethanol emissions measured from CSP, TMR, and LCS. On the other hand, except for being able to predict the high emissions measured during the first hour, model predictions were low compared to measured data for SB ethanol emissions, very low for CSP and SB methanol emissions, and very high for TMR methanol emissions. These discrepancies demonstrate the importance of refining mass transport parameters with respect to silage and environmental conditions, and possibly the need to account for changes in silage face conditions after defacing. Despite these uncertainties, the model is a valuable tool for comparing relative effects of different strategies for storing and 
feeding silage. As a component of a whole-farm simulation model, silage management effects on VOC emissions were simulated on a representative dairy farm in California. Simulations indicate that most of the reactive VOC emissions occur from feed lying in feed lanes as opposed to the exposed face of silage storages. This implies that mitigation efforts focused on reducing emissions from the feed bunk will be most effective in reducing whole farm VOC emissions. With less exposed face, use of silage bags also has the potential to significantly reduce overall emissions from the whole farm.

Further research can improve the accuracy and application of the model. Experimental data are needed to refine mass transport parameters for more accurate prediction of important silage VOCs other than ethanol. The on-farm data available for silage VOC emissions, including this study, have been measured with very low air movement. Measurement of emissions at ambient conditions is necessary to further evaluate and/or refine the model's sensitivity to air flow over silage surfaces.

\section{Acknowledgments}

This research was funded by the California Air Resources Board (Contract No. 11-325) and USDA Agricultural Research Service. Cooperation of the dairy owner in the San Joaquin Valley in making this study possible is also acknowledged and much appreciated.

\section{References}

Alanis, P., Sorenson, M., Beene, M., Krauter, C., Shamp, B., Hasson, A., 2008. Measurement of non-enteric emission fluxes of volatile fatty acids from a California dairy by solid phase micro-extraction with gas chromatography/mass spectrometry. Atmospheric Environment $42,6417-6424$. 
Buckmaster, D.R., 2005. TMR delivery and variability on the farm. In: Dairy Cattle Nutrition Workshop 2005 Proceedings, Grantville, PA. 9 - 10 November, 2005. http://extension.psu.edu/animals/dairy/courses/dairy-cattle-nutrition-workshop/previousworkshops.

Carter, W.P., 2009. Development of the SAPRC-07 Chemical Mechanism and Updated Ozone Reactivity Scales. Tech. Rep. Final Report to the California Air Resources Board Contract No. 03-318. Center for Environmental Research and Technology, College of Engineering, University of California. URL. http://www.engr.ucr.edu/ carter/SAPRC/.

Chung, M.Y., Beene, M., Ashkan, S., Krauter, C., Hasson, A.S., 2010. Evaluation of non-enteric sources of non-methane volatile organic compound (NMVOC) emissions from dairies. Atmospheric Environment 44, 786-794.

Crank, J., 1975. The Mathematics of Diffusion. 2nd ed. Clarendon Press, Oxford.

Deacon, E.L., 1977. Gas transfer to and across an air-water interface. Tellus 29, 363-374.

El-Mashad, H.M., Zhang, R., Rumsey, T., Hafner, S., Montes, F., Rotz, C.A., Arteaga, V., Zhao, Y., Mitloehner, F.M., 2010. A mass transfer model of ethanol emission from thin layers of corn silage. Transactions of the ASABE 53 (6), 1903-1909.

Glasgow, L.A., 2010. Transport Phenomena. John Wiley \& Sons, Inc., Hoboken, New Jersey. Hafner, S.D., Franco, R.B., Kung Jr., L., Rotz, C.A., Mitloehner, F., 2014. Potassium sorbate reduces production of ethanol and 2 esters in corn silage. Journal of Dairy Science 97, $7870-7878$.

Hafner, S.D., Howard, C., Muck, R.E., Franco, R.B., Montes, F., Green, P.G., Mitloehner, F., Trabue, S.L., Rotz, C.A., 2013. Emission of volatile organic compounds from silage: Compounds, sources, and implications. Atmospheric Environment 77, 827-839. 
Hafner, S.D., Montes, F., Rotz, C.A., 2012. A mass transfer model for VOC emission from silage. Atmospheric Environment 54, 134-140.

Hafner, S.D., Montes, F., Rotz, C.A., 2009. Modeling emissions of volatile organic compounds. In: 2009 ASABE Annual International Meeting, Reno, NV. 21 - 24 June, 2009. ASAPE Paper No. 095967.

Hafner, S.D., Montes, F., Rotz, C.A., Mitloehner, F.M., 2010a. A farm-level model of VOC emission from silage. In: International Symposium on Air Quality and Manure Management for Agriculture, Dallas, TX. 13 - 16 September, 2010. ASABE Publication No. 711P0510cd.

Hafner, S.D., Montes, F., Rotz, C.A., Mitloehner, F.M., 2010b. Ethanol emission from loose corn silage and exposed silage particles. Atmospheric Environment 44, 4172-4180.

Howard, C., Kumar, A., Malkina, I., Mitloehner, F., Green, P., Flocchini, R., Kleeman, M., 2010. Reactive organic has emissions from livestock feed contribute significantly to ozone production in central California. Environmental Science \& Technology 44, 2309-2314.

Malkina, I.L., Kumar, A., Green, P.G., Mitloehner, F.M., 2011. Identification and quantitation of volatile organic compounds emitted from dairy silages and other feedstuffs. Journal of Environmental Quality 40, 28-36.

Mitloehner, F., Cohen, M., Zhang, R., Zhao, Y., Pan, Y., Lin, X., Green, P., Rotz, A., Hafner, S., Bonifacio, H., Kung, L., 2016. Quantification of the emission reduction benefits of mitigation strategies for dairy silage: Final report. California Air Resources Board, Sacramento, CA. https://www.arb.ca.gov/research/apr/past/11-325.pdf. 
Montes, F., Hafner, S.D., Rotz, C.A., Mitloehner, F.M., 2010. Temperature and air velocity effects on ethanol emission from corn silage with the characteristics of an exposed silo face. Atmospheric Environment 44, 1987-1995.

Muck, R.E., Holmes, B.J., 2006. Bag silo densities and losses. Transaction of the ASABE 49 (5), $1277-1284$.

Muck, R.E., Rotz, C.A., 1996. Bunker silo unloaders: An economic comparison. Transactions of the ASAE 12 (3), 273-280.

Ohman, D., Henry, J., Hinen, J., Keister, B., Miller, J., Oelberg, T., Rodriguez, R., Wood, M., 2007. Monsanto dairy silage bunker surveys and study. Forage Focus. http://www.midwestforage.org/pdf/213.pdf.pdf.

Roach, J.M., Kammel, D.W., 2012. Drive-over silage pile construction. http://www.extension.org/pages/64621/drive-over-silage-pileconstruction\#.VebtMvlVhBc.

Robinson, P.H., Swanepoel, N., Heguy, J.M., Price, T., Meyer, D.M., 2016. 'Shrink' losses in commercially sized corn silage pile: Quantifying total losses and where they occur. Science of the Total Environment 542, 530-539.

Rotz, C.A., Corson, M.S., Chianese, D.S., Montes, F., Hafner, S.D., Bonifacio, H.F., Coiner, C.U., 2016. The Integrated Farm System Model: Reference Manual, Version 4.3. United States Department of Agriculture-Agricultural Research Service, University Park, PA. URL. https://www.ars.usda.gov/ARSUserFiles/80700500/Reference\%20Manual.pdf. San Joaquin Valley Air Pollution Control District (SJVAPD), 2016. Report to the Community 2015-2016. SJVAPD, Fresno, CA. https://www.valleyair.org/General_info/pubdocs/2015-Annual-Report-WEB.PDF. 
Savoie, P., Jofriet, J., 2003. Silage storage. In: Silage Science and Technology. Agronomy Monograph No. 42. American Society of Agronomy, Inc., Crop Science Society of America, Inc., Soil Science Society of America, Inc., Madison, WI.

Silva-del-Rio, N., 2010. Opportunities to improve corn silage in California. In: 2010 California Alfalfa \& Forage Symposium, Visalia, CA. 30 November - 2 December, 2010.

Sun, H., Pan, Y., Zhao, Y., Jackson, W.A., Nuckles, L.M., Malkina, I.L., Arteaga, V.E., Mitloehner, F.M., 2008. Effects of sodium bisulfate on alcohol, amine, and ammonia emissions from dairy slurry. Journal of Environmental Quality 37, 608-614.

U.S. Environmental Protection Agency (USEPA), 2016. Criteria Air Pollutants. USEPA, Washington, DC. https://www.epa.gov/criteria-air-pollutants.

Warneck, P., 2006. A note on the temperature dependence of Henry's Law coefficients for methanol and ethanol. Atmospheric Environment 40, 7146-7151.

Weiss, K., Auerbach, H., 2015. The influence of additives on fermentation pattern, volatile organic compounds (VOCs) and aerobic stability of grass silage. In: Proceedings of the XVII International Silage Conference, Piracicaba, Sao Paulo, Brazil. 1 - 3 July, 2015.

Weiss, K., Bruning, D., Kalzendorf, C., 2015a. The influence of air ingress and additives on fermentation pattern, volatile organic compounds (VOCs) and aerobic stability of maize silage. In: Proceedings of the XVII International Silage Conference, Piracicaba, Sao Paulo, Brazil. 1 - 3 July, 2015.

Weiss, K., Olbrich, C., Thaysen, J., 2015b. Volatile organic compounds (VOC) in maize silages at German dairy farms. In: Proceedings of the XVII International Silage Conference, Piracicaba, Sao Paulo, Brazil. 1 - 3 July, 2015. 
Willmott, C.J., Robeson, S.M., Matsuura, K., 2012. Short communication - A refined index of model performance. International Journal of Climatology 32, 2088-2094.

Zhang, R., Mitloehner, F., El-Mashad, H., Malkina, I., Rumsey, T., Arteaga, V., Zhu, B., Zhao, Y., Goldstein, A., Matross, D., Hafner, S., Montes, F., Rotz, C.A., 2010. Process-based farm emission model for estimating volatile organic compound emissions from California dairies: Final research project report. California Air Resources Board, Sacramento, CA. https://www.arb.ca.gov/research/apr/past/05-344.pdf. 